\title{
Dynamic Performance Enhancement and Comparative Analysis of Fault Tolerant Five Phase Induction Motor using PSO and GWO Algorithms
}

\author{
Chandani Gor*, Varsha Shah \\ Department of Electrical Engineering, S. V. National Institute of Technology, Surat-395007, India.
}

\begin{abstract}
The multiphase induction motor is a highly preferable choice for the electric vehicle application where the reliability and safety of passengers are one of the major concerns. In such safety critical applications, it is necessary to have the smooth speed transition under the occurrence of fault with minimum disturbance in the system. Therefore this paper proposes GWO (Grey Wolf Optimization) based optimal speed controller, which deals with fault tolerant mode of operation in rotor field oriented controlled (RFOC) five phase induction motor (FPIM). In this paper an open phase fault on FPIM is considered due to leg switches failure in the power electronic converter. It is modeled by applying back EMF calculation in faulty phase, which minimizes the controller reconfiguration under fault. The motive of the paper is to optimize the speed controller gains to enhance the controller performance against the uncertainties of fault occurrence and application of fault tolerant technique in FPIM. Hence this work proposes an application of GWO (Grey Wolf Optimization) algorithm to finely tune speed controller gains which will generate optimal torque reference under all such disturbances. The superiority of algorithm is proved by comparing its performance with standard PSO (Particle swarm optimization) algorithm under healthy, faulty and fault tolerant modes of operations. The comparative analysis of both the algorithms is presented considering their convergent time, number of parameters needed as well as time response parameters and calculation of various performance indices under different modes of operations. The simulation results and comparative analysis prove the effectiveness of GWO algorithm to enhance different speed tracking performances under healthy, faulty and fault tolerant modes of operation.
\end{abstract}

Keywords - Electric Vehicle, Fault Tolerance, Five Phase Induction Motor (FPIM), Optimization, PSO, GWO

\section{INTRODUCTION}

The important criterion for designing an electric vehicle drive is to provide a safe and reliable solution with reasonable cost. Extensive research has been done on proper selection of electric propulsion drive. The higher phase (more than 3 phases) induction motors can be the preferable selection as a propulsion drive of electric vehicle [1]. For the reliable operation in fault tolerant mode, three phase counterpart results into over dimensioned size with increased cost [2]. Whereas the multiphase motors does not require additional hardware arrangement for sustained operation under fault [3]. In the electric vehicle drive system the major fault prone locations are the inverter, condition monitoring circuits and the electric motor are as shown in fig. 1. The effect of faults in stator and rotor windings as well as sensor fault is same in case of all drive system irrespective of phase number. In the electric drive system the power converter faults are more prominent and can affect the entire system behavior. As shown in fig. 1, they can be again classified as gate failure, switch short circuit (SSC) or open circuit (SOC) fault, phase leg open (PLO) or short (PLS) fault, or line open fault. These kinds of faults can occur due to the burning of switches. In the literature, various control techniques like FOC (field oriented control) [4-6], MPC (model predictive control) [7], proportional resonant controller (PR) [8,9], direct torque control [10] and others are addressed for fault tolerant control in multiphase induction motor.

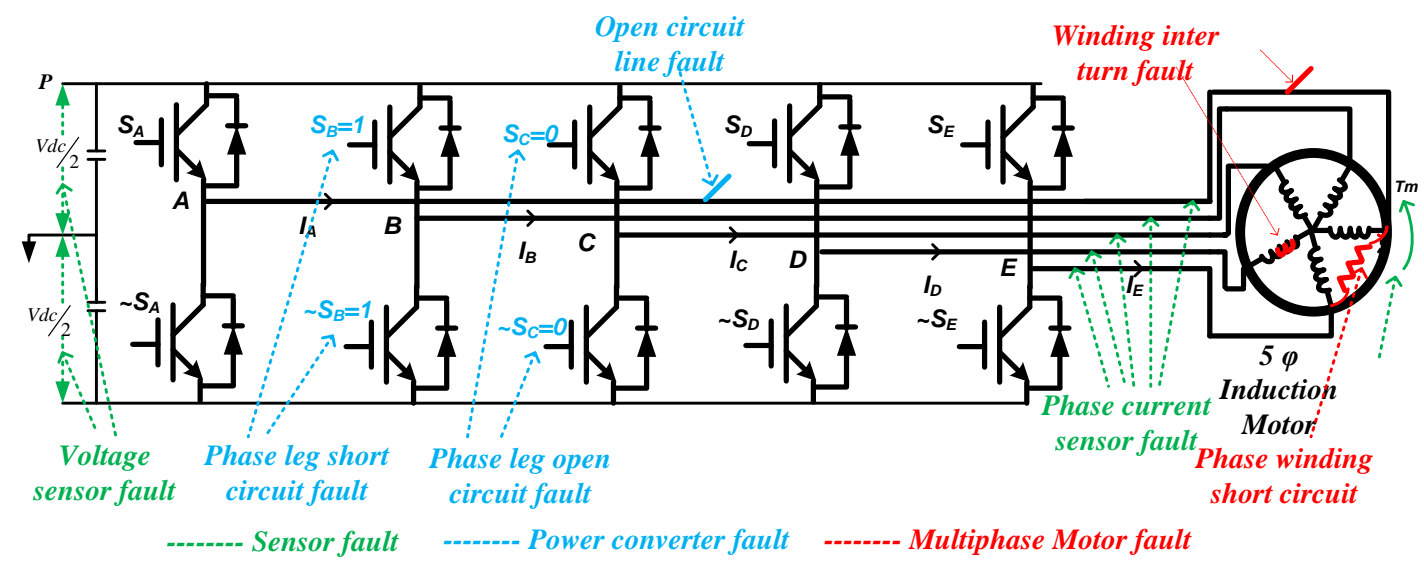

Figure 1. Different faults in FPIM drive 
In past few years different nonlinear control techniques such as adaptive control, variable structure control and other artificial intelligent control techniques have become popular among the researchers in motor drive control applications. But their practical applications are limited due to their complicated structure, difficulty of real time implementation and stability related issues [11]. The conventional PI controller is widely in use due to its simple structure and ease of implementation. The tuning of PI speed controller is very important for indirect field oriented control of FPIM as the controller output generates the proper torque reference which in turn generates the unit vectors for proper decoupling of flux and torque components of current. However their tuning is tedious and takes significant time. There are many methods of estimating PI-controller gains are reported in literature [12]. In most of the techniques, it is necessary to assume certain parameters and need the knowledge of work experience. Instead, in the optimization-based methods for PI gain tuning, the algorithm converges to the minimum value in predefined number of iteration with initial random guess.

Recently a metaheuristic based algorithm grey wolf optimization (GWO) has become popular in some optimization problems. The advantage of the algorithm is that, it requires reduced number of parameters for the optimization process. It is derived from the hunting technique of grey wolf to find its prey [12]. As per the algorithm search agents are divided into four different groups. The search process takes place in three stages of searching, encircling and attacking the prey. There are few electrical engineering applications reported in literature using GWO algorithm. In [13] the GWO algorithm is used for planning the security of smart grid. The algorithm is used to calculate the best combination of control variables optimal reactive power dispatch problem in [14]. Use of the same algorithm for realizing the maximum power point tracking is reported in [15]. However, the application of GWO algorithm for speed controller optimization in multiphase induction motor is not been reported yet. Therefore, this paper investigates the suitability and superiority of GWO algorithm for enhancement of dynamic performance in fault tolerant FPIM.

The objective of this paper is to find out optimal speed PI controller gains using GWO optimization technique and its comparison with PSO algorithm for the fault tolerant speed control of FPIM drive under dynamically varying speed and load demand problem. The aim of the optimization methods to improve dynamic and steady state response of FPIM under healthy, faulty and fault tolerant mode of operation. Therefore the Integral Time Square Error (ITSE) criterion is used as optimization function. The performance of the techniques in terms of convergence rate, steady state error minimization and time complexity are compared with other methods listed in the literature.

The above attempt is achieved all through the following points.

1) To facilitate that a prototype $2 \mathrm{HP}$ five phase induction motor model is formed in $\mathrm{d}-\mathrm{q}$ frame under faulty phase condition. The fault is modeled by considering the back EMF calculation in faulty phase under one phase open circuit condition;

2) The post fault currents are obtained by considering the circular trajectory of stator $\mathrm{d}-\mathrm{q}$ flux to remain unchanged. In order to get the modified current reference under fault condition the non-energy current components are utilized as weighted energy current components;

3) The minimum torque ripples criterion is selected to decide the corresponding weight factor for the new reference currents generation;

4) Based on the preceding model PSO and GWO algorithms are applied to optimize speed controller in indirect vector controlled FPIM for healthy and faulty condition;

5) Verify and compares the robustness of the PI controller with gains obtained using the optimization methods under different healthy, faulty and fault tolerant conditions;

In summary the main accusative of this work is to design optimized robust speed controller which works equally well with healthy and open circuit fault condition of the FPIM drive for electric vehicle. Robustness of the proposed controller in healthy and faulty condition at various operating points is verified through simulation results. The paper has been conferred in following pattern. Section II presents five phase induction motor modeling under healthy and faulty condition Section III discusses control of FPIM under fault tolerant mode of operation. In section IV presents optimization of speed PI controller through PSO and GWO algorithm is discussed. In Section $V$ the effectiveness of proposed technique is verified via various simulation results under different operating condition.

\section{FPIM MODELLING}

In this section modeling of FPIM in normal and faulty condition is presented.

\section{II.I FPIM modeling in normal condition}

The time varying inductances in voltage, current and flux equation of the multiphase machine are removed using transformation matrix in (2). The conversion reduces the multiphase winding of the motor to a set of two phase winding

$\left[U_{\alpha \beta x y 0}\right]=\left[T_{s}\right]\left[U_{\text {abcde }}\right]$

$$
T_{s}=\sqrt{2 / 5}\left[\begin{array}{ccccc}
1 & \cos (\gamma) & \cos (2 \gamma) & \cos (2 \gamma) & \cos (\gamma) \\
0 & -\sin (\gamma) & -\sin (2 \gamma) & \sin (2 \gamma) & \sin (\gamma) \\
1 & \cos (2 \gamma) & \cos (\gamma) & \cos (\gamma) & \cos (2 \gamma) \\
0 & \sin (2 \gamma) & -\sin (\gamma) & \sin (\gamma) & -\sin (2 \gamma) \\
\sqrt{1 / 2} & \sqrt{1 / 2} & \sqrt{1 / 2} & \sqrt{1 / 2} & \sqrt{1 / 2}
\end{array}\right]
$$

The $\alpha-\beta$ plane is connected with energy conversion variables and responsible for fundamental torque development. The $x-y$ plane is associated with loss producing components. The last row is associated with the 
zero sequence components, which may be ignored for an isolated neutral point. The rotor is short circuited. So rotor $x-y$ components are absent. The angle in transformation matrix, $\gamma=2 \pi / 5$. The $\alpha-\beta$ equations are further rotated to synchronous reference frame and the model equations are shown below. The $x-y$ components do not link with rotor and contribute to torque, so they are not rotated.

$V_{d s}=R_{s} I_{d s}+\frac{d \psi_{d s}}{d t}-\omega_{f} \psi_{q s}, V_{x s}=R_{s} I_{x s}+\frac{d \psi_{x s}}{d t}$

$V_{q s}=R_{s} I_{q s}+\frac{d \psi_{q s}}{d t}+\omega_{f} \psi_{d s}, V_{y s}=R_{s} I_{y s}+\frac{d \psi_{y s}}{d t}$,

$V_{0 s}=R_{s} I_{0 s}+\frac{d \psi_{0 s}}{d t}$

$\left.V_{d r}=R_{r} I_{d r}+\frac{d \psi_{d r}}{d t}-\psi_{q s}\left(\omega_{f}-\omega_{r}\right)=0\right)$

$\left.V_{q r}=R_{r} I_{q r}+\frac{d \psi_{q r}}{d t}+\psi_{d s}\left(\omega_{f}-\omega_{r}\right)=0\right\}$

The flux linkage expressions with iron losses neglected are,

$\left.\begin{array}{l}\psi_{d s}=L_{s} I_{d s}+L_{m} I_{d r} \\ \psi_{q s}=L_{s} I_{q s}+L_{m} I\end{array}\right\}$

$\psi_{x s}=L_{l s} I_{x s}$

$\left.\psi_{y s}=L_{l s} I_{y s}\right\}$

$\psi_{d r}=L_{m} I_{d s}+L_{r} I_{d r}$

$\left.\psi_{q r}=L_{m} I_{q s}+L_{r} I_{q r}\right\}$

$\psi_{x r}=L_{l r} I_{x r}$

$\left.\psi_{y r}=L_{l r} I_{y r}\right\}$

The above terms are rearranged to obtain the state space model of motor as shown in (11). The developed torque is expressed as

$$
T_{e}=P \frac{L_{m}}{L_{r}}\left(\psi_{d r} i_{q s}-\psi_{q r} i_{d s}\right)
$$

Torque balancing equation is

$$
\begin{gathered}
J \frac{d \omega_{r}}{d t}+B \omega_{r}=T_{e}-T_{L} \\
\frac{d}{d t}\left[\begin{array}{c}
I_{d s} \\
I_{q s} \\
\psi_{d r} \\
\psi_{q r}
\end{array}\right]=[A]\left[\begin{array}{c}
I_{d s} \\
I_{q s} \\
\psi_{d r} \\
\psi_{q r}
\end{array}\right]+[B]\left[\begin{array}{c}
V_{d s} \\
V_{q s}
\end{array}\right]
\end{gathered}
$$

$$
\begin{aligned}
& \text { where, }[A]=\left[\begin{array}{cccc}
-a_{1} & \omega_{f} & a_{2} & p a_{3} \omega_{r} \\
-\omega_{f} & -a_{1} & p a_{3} \omega_{r} & a_{2} \\
a_{5} & 0 & -a_{4} & \omega_{s l} \\
0 & a_{5} & -\omega_{s l} & -a_{4}
\end{array}\right],[B]=\left[\begin{array}{cc}
c & 0 \\
0 & c \\
0 & 0 \\
0 & 0
\end{array}\right] \\
& \sigma=1-\frac{L_{m}^{2}}{L_{r} L_{s}}, a_{1}=\frac{1}{\sigma L_{s}}\left(R_{s}+R_{r} \frac{L_{m}^{2}}{L_{r}^{2}}\right), a_{2}=\frac{1}{\sigma L_{s}} R_{r} \frac{L_{m}^{2}}{L_{r}^{2}}, \\
& a_{3}=\frac{1}{\sigma L_{s}} \frac{L_{m}}{L_{r}}, a_{4}=\frac{R_{r}}{L_{r}}, a_{5}=\frac{R_{r} L_{m}}{L_{r}}, \\
& \omega_{f}-p \omega=\omega_{s l}, c=\frac{1}{\sigma L_{s}}
\end{aligned}
$$

\section{II.II FPIM modeling under fault condition}

In this paper open circuit fault is modeled. For the symmetric and distributed winding of the FPIM, the fault is assumed due to breakdown of inverter leg switches. There are various approaches reported in the literature to model the faulty phase of FPIM. One is to use the conventional Ks in healthy state, and reduced order matrix under faulty state 18 . The other approach is to use Back EMF calculation in faulty phase and apply as an input at the time of fault occurrence. In this paper second approach is used for modeling the fault, which in turn minimizes the changes in controller reconfiguration. By expanding (2), following dependencies can be obtained.

$$
\begin{aligned}
U_{\alpha s} & =\sqrt{\frac{2}{5}}\left(\begin{array}{l}
U_{a s}+U_{b s} \cos (\gamma)+U_{c s} \cos (2 \gamma) \\
+U_{d s} \cos (2 \gamma)+U_{e s} \cos (\gamma)
\end{array}\right) \\
U_{\beta s} & =\sqrt{\frac{2}{5}}\left(\begin{array}{l}
-U_{b s} \sin (\gamma)-U_{c s} \sin (2 \gamma) \\
+U_{d s} \sin (2 \gamma)+U_{e s} \sin (\gamma)
\end{array}\right) \\
U_{x s} & =\sqrt{\frac{2}{5}}\left(\begin{array}{l}
U_{a s}+U_{b s} \cos (2 \gamma)+U_{c s} \cos (\gamma)+ \\
U_{d s} \cos (\gamma)+U_{e s} \cos (2 \gamma)
\end{array}\right) \\
U_{y s} & =\sqrt{\frac{2}{5}}\left(\begin{array}{l}
U_{b s} \sin (2 \gamma)- \\
U_{c s} \sin (\gamma)+U_{d s} \sin (\gamma)-U_{e s} \sin (2 \gamma)
\end{array}\right) \\
U_{0 s} & =\sqrt{\frac{1}{5}}\left(\begin{array}{l}
\left.U_{a s}+U_{b s}+U_{c s}+U_{d s}+U_{e s}\right)
\end{array}\right.
\end{aligned}
$$

In the above equation the variable ' $U$ ' describes current and voltage. When phase ' $a$ ' is lost, the machine voltages become unbalanced. The following dependencies can be derived:

$$
\begin{gathered}
U_{\alpha s}+U_{x s}=2 \sqrt{\frac{2}{5}}\left(U_{a s}\right)+\sqrt{\frac{2}{5}}\left(U_{b s}+U_{c s}+U_{d s}+U_{e s}\right) \\
\cdot(\cos (\gamma)+\cos (2 \gamma)) \\
U_{\alpha s}-U_{x s}=\sqrt{\frac{2}{5}}\left(U_{b s}-U_{c s}-U_{d s}+U_{e s}\right) \\
*(\cos (\gamma)+\cos (2 \gamma))=\mathrm{E}
\end{gathered}
$$


The unknown current and voltage relationship is obtained from (17) and (18) respectively. Considering current in faulty phase $i_{a s}=0$ and the star connected stator of the motor results in (19).

$$
i_{\alpha s}+i_{x s}=0 \Rightarrow i_{x s}=-i_{\alpha s}
$$

$v_{x s}$ is obtained by substituting (19) in (6) as,

$$
v_{x s}=-R_{s} i_{\alpha s}-\frac{d}{d t} L_{l s} i_{\alpha s}
$$

The (20) is substituted in (17) results in $v_{\alpha s}$, which is used to obtain the open phase fault in the FPIM drive.

$$
\begin{array}{r}
v_{\alpha s}=\sqrt{\frac{2}{5}}\left(\left(v_{b s}+v_{e s}-v_{c s}-v_{d s}\right) *(\cos (2 \gamma)+\cos (\gamma))\right. \\
\left(R_{s} i_{\alpha s}+\frac{d}{d t} L_{l s} i_{\alpha s}\right)
\end{array}
$$

\section{FPIM CONTROL SCHEME}

The FPIM control under healthy and faulty condition is obtained using rotor oriented field oriented control technique. The detail of control technique under healthy and modified technique under open phase fault condition is described in this section.

\section{III.I Prefault operation under normal condition}

Under normal condition, the $\alpha-\beta$ current components are only responsible for the average torque production. The $x-y$ components do not contribute to the energy conversion process. Therefore only the $\alpha-\beta$ currents are used for reference current generation while the $x-y$ current components are regulated to zero. For the five phase induction motor, the RFOC is obtained as follows. The rotor flux orientation angle is calculated in (22). The slip speed is obtained as in (23). The reference currents are generated as in (24).

$$
\begin{aligned}
& \theta_{\psi_{r}}=\int \omega_{s} d t=\int\left(\omega_{s l}+\omega_{r}\right) d t \\
& \omega_{s l}=\left(\frac{1+P \tau_{r}}{\tau_{r}}\right)\left(\frac{i_{q s}^{*}}{i_{d s}^{*}}\right) \\
& i_{d s}^{*}=\frac{\psi_{d r}^{*}}{L_{m}}, i_{q s}^{*}=\frac{T_{e}^{*}}{k_{t} i_{d s}}, \text { where } k_{t}=\frac{5 P L_{m}^{2}}{4 L_{r}}
\end{aligned}
$$

The detailed scheme used for the RFOC control of FPIM under healthy and faulty condition is shown in Fig $2 \mathrm{a}$. Under healthy condition $i_{x}^{*}$ and $i_{y}^{*}$ are regulated to zero value. The hysteresis current controllers are used to generate the switching pulses.

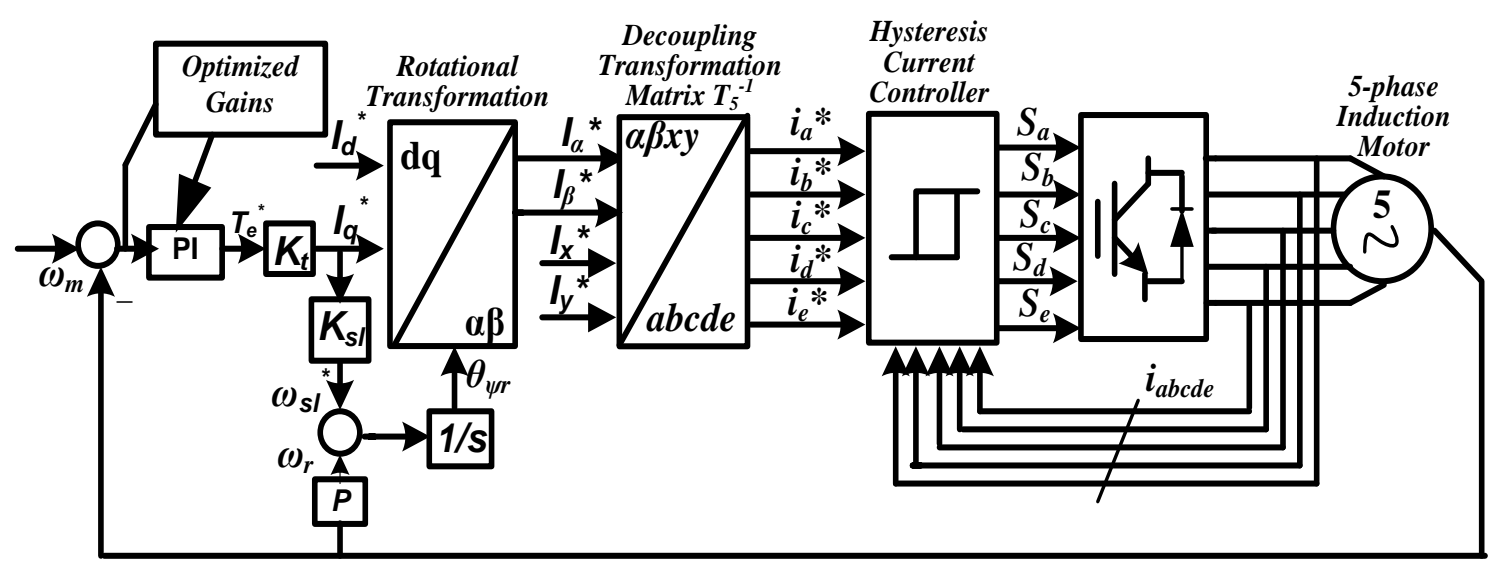

Figure 2a. The complete RFOC scheme for FPIM

\section{III.II Modified RFOC under open phase fault}

The model of the faulted five phase motor is obtained by calculating the back EMF in the faulted phase of the machine as explained in previous section. The calculated back EMF in faulty phase is applied as an input to realize the fault condition. Under the fault condition the rest of the healthy phase currents become unbalanced and their magnitudes increase to larger than their rated value. This in turn results in additional torque ripples which intolerant for vehicular system. Therefore after occurrence of fault it is necessary to redefine reference currents which can result in smooth operation of motor under post fault condition. 
For the star connected FPIM with isolated neutral point zero sequence components remain zero. The non energy currents $i_{x}$ and $i_{y}$ are used to generate proper reference phase currents which will compensate for the distortion. This is obtained by following dependency as in (25):

$$
\left.\begin{array}{l}
i_{x}^{*}=w_{1} i_{\alpha}^{*}+w_{2} i_{\beta}^{*} \\
i_{y}^{*}=w_{3} i_{\alpha}^{*}+w_{4} i_{\beta}^{*}
\end{array}\right\}
$$

There are different $w_{1}-w_{4}$ possible to form rotational magnetic flux trajectory, which will result in different modes of drive operation like minimum torque ripple or maximum efficiency. In this case for vehicle application $w_{1}-w_{4}$ are found by considering the minimum torque ripple in the system. The current in faulty phase is zero, which is used to establish a relation between $i_{\alpha}$ and $i_{x}$. That gives the value of $w_{1}=-1$. For making the analysis easy $w_{2}=0$ is considered.

The values of $w_{3}$ and $w_{4}$ are calculated as -0.2631 and 0 respectively. The corresponding reference current generation is shown in Fig $2 b$.
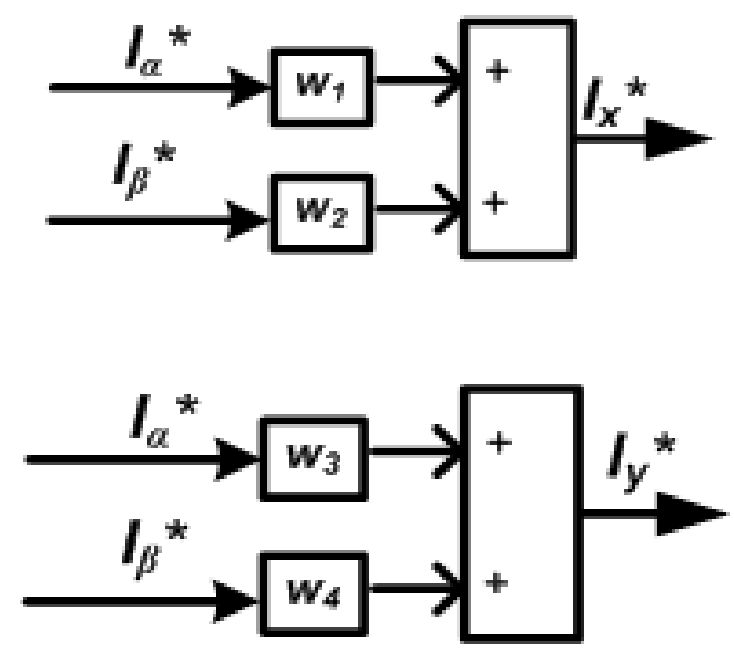

Figure 2b $x-y$ reference current formation under fault tolerant operation

\section{SPEED CONTROLLER DESIGN AND ITS OPTIMIZATION}

\section{IV.I Conventional PI controller for FPIM}

The conventional PI controllers are widely used in the industrial application as their parameters are directly associated with the system response specifications. Selection of appropriate parameters influences the speed response, overshoot, settling time and load rejection behavior of the drive. However all the required performance characteristics cannot be achieved at the same time using the same parameters [19].

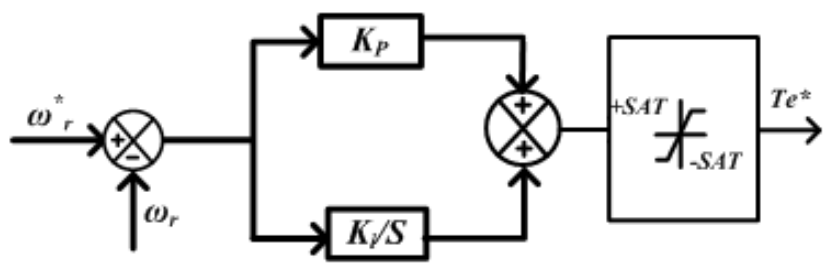

Figure 3. Schematic of PI speed controller

Fig 3 shows schematic model of the PI speed controller. The controller functioning is explained in (27). The speed error is generated from difference of reference and actual speed command.

$$
\left.\begin{array}{l}
\Delta \omega_{r}(t)=\omega_{r}^{*}(t)-\omega_{r}(t) \\
T_{e}^{*}=K_{p} \Delta \omega_{r}(t)+K_{i} \int \Delta \omega_{r}(t) d t
\end{array}\right\}
$$

The speed error is processed through PI speed controller. The output of PI controller is interpreted reference torque command, which is further applied to limiter as in (28) for final torque command generation. The limiter ensures the output torque and so the current of the inverter remains within the safe range.

$$
T_{e}^{*}= \begin{cases}T_{e \max }^{*} & \text { for } T_{e}^{*} \geq T_{e \max }^{*} \\ -T_{e \min }^{*} & \text { for } T_{e}^{*} \leq T_{e \min }^{*}\end{cases}
$$

Where, $\Delta \omega_{r}(t)$ is the error speed, $K_{p}$ is proportional and $K_{i}$ is the integral gain constants. $T_{e}^{*}$ is the reference torque component, $\omega_{r}^{*}(t)$ and $\omega_{r}(t)$ are the reference speed and actual speed, respectively.

\section{IV.II Speed controller gain optimization}

The metaheuristics techniques are applied for tuning the gains of the PI speed controller due to their simplicity and mathematical complexity free mechanism. In this research work two different optimization techniques, PSO and GWO are employed for obtaining optimized proportional and integral gains for the fault tolerant operation of FPIM. The paper considers ITSE (integral time square error) based objective or fitness function as shown in (29). The purpose of the stochastic algorithms is to minimize the objective function ' $F$ ' by evaluating the speed error of the FPIM over the total simulation time $T_{\text {final }}$. All particles of the population are decoded for $K p$ and $K i$ of the speed controller.

$$
F=\int_{0}^{T_{\text {final }}} t *\left|\Delta \omega_{r}\right|^{2} d t
$$$$
\text { where, } T_{\text {final }}=T_{\text {healthy }}+T_{\text {fault }}+T_{\text {withFTT }}
$$

\section{IV.II.I Optimization using PSO}

The PSO (particle swarm optimization) algorithm is a robust method of optimization based on the movement of swarms and abstracts the working mechanism of swarms of birds, 
fishes etc. The algorithm takes several particles in the search space. Each particle continuously updates its position based on the behavior of its own experience as well as its neighbors'. That means it takes the feedback from both local and global best position and in turn it is a combination of local best and global best position. There are mainly three vectors are initialized as position vector ' $x$ ', velocity vector ' $v$ ' and particle best position ' $p$ ' for all the particles. They are continuously updated for the prescribed number of iterations.

\section{a) PSO algorithm implementation}

The frame work of the algorithm is shown in fig 4 as a flow chart. As explained in fig 4, the algorithm randomly initializes certain number of particles in the solution space so that the entire search area is covered and defined as $x_{0}$.

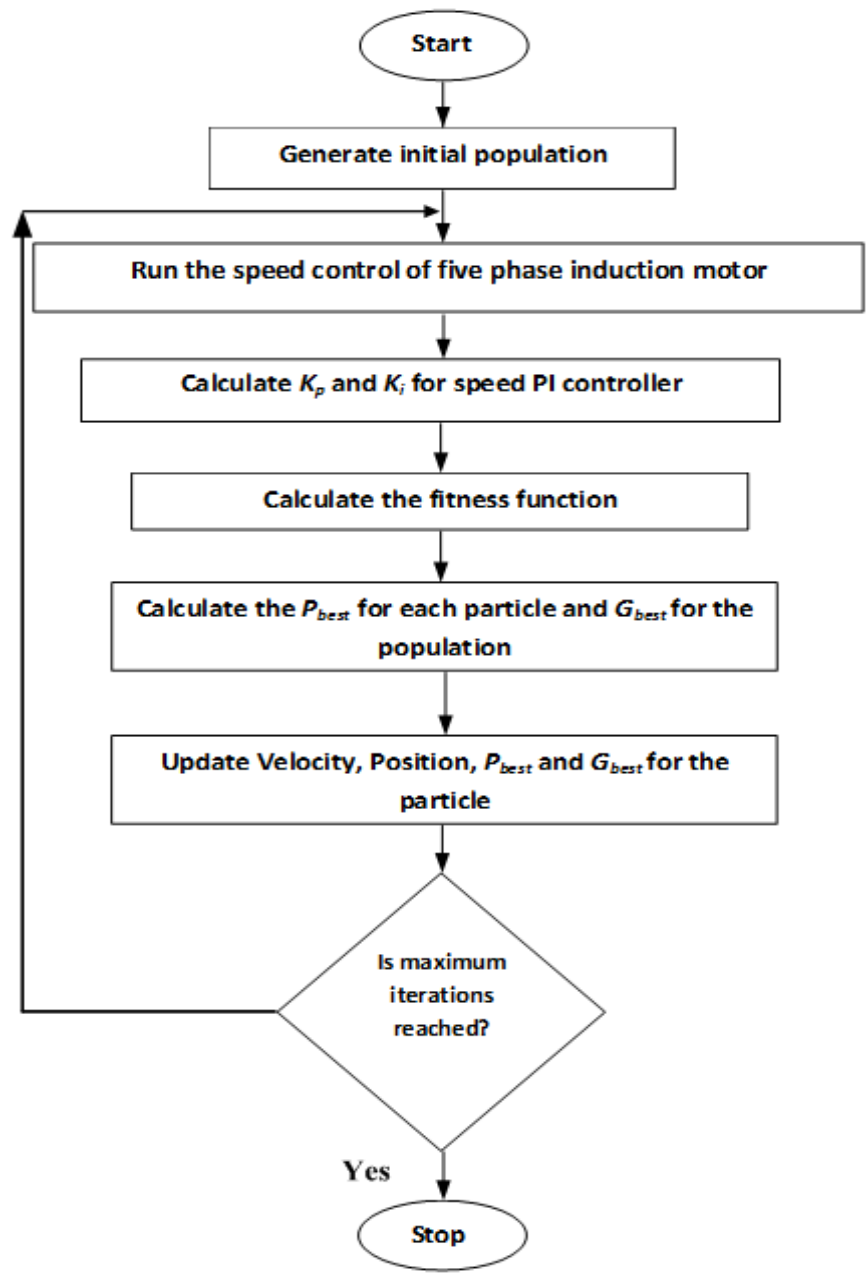

Figure 4. Frame work of the PSO algorithm

Their initial velocities are calculated as $v_{0}$. The fitness is evaluated for each particle. The fitness of the cost function is compared with the local and global best solution pbest and gbest respectively. They are continuously updated if fitness is found better than them. Where, 'pbest' is the best position found by the each particle and 'gbest' is the best position found by all the particles. Fig 5 shows the search procedure in an ' $n$ ' dimensional space.

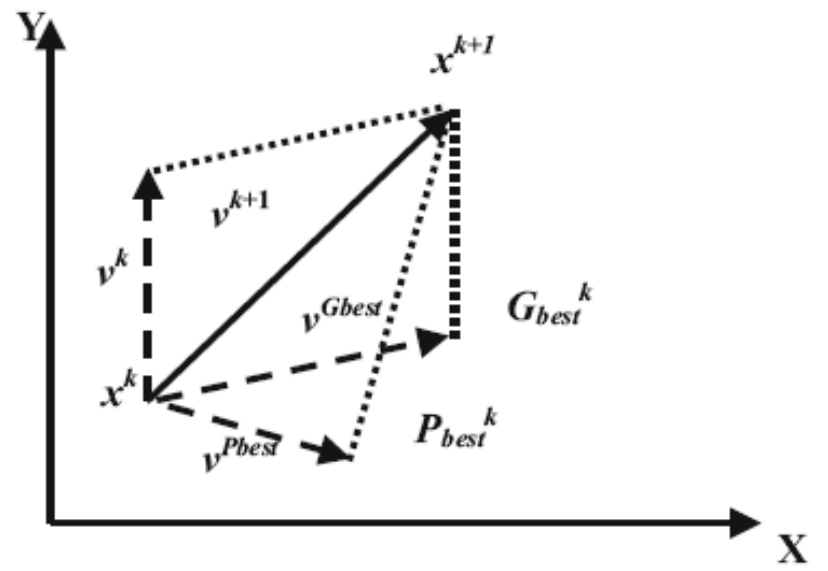

Figure 5. Best position search procedure in ' $n$ ' dimensional space

The particles are initialized as follows as in (30). The change in position of the particle is obtained by the means of velocities. The velocity of particles is initialized as given in (31).

$$
\begin{gathered}
p_{0}=p_{\text {min }}+r_{1}(0,1) \cdot\left(p_{\text {max }}-p_{\text {min }}\right) \\
v_{0}=v_{\text {min }}+r_{2}(0,1) \cdot\left(v_{\max }-v_{\text {min }}\right)
\end{gathered}
$$

If the termination criterion does not meet, the new velocities are calculated using (32). The new position of the particle is obtained using (33). This is done for all the initialized particles and for prescribed number of iteration.

$$
\begin{gathered}
v_{i, d}^{t+1}=w_{i} \cdot v_{i, d}^{t}+b_{1} \cdot \operatorname{rand}_{1}(0,1) \cdot\left(p_{\text {best }}-x_{i, d}^{t}\right) \\
+b_{2} \cdot \operatorname{rand}_{2}(0,1) \cdot\left(g_{\text {best }}-x_{i, d}^{t}\right) \\
x_{i, d}^{t+1}=x_{i, d}^{t}+v_{i, d}^{t+1}
\end{gathered}
$$

Where, $x_{i, d}^{t}$ is the current searching position of ' $d$ ' dimension in ' $i$ 'th' iteration and $x_{i, d}^{t+1}$ is updated searching position. Similarly $v_{i, d}^{t}$ and $v_{i, d}^{t+1}$ can be defined for velocities. $w_{i}$ is the inertial weight which is updated for each iteration using (34). The constants $b_{1}$ and $b_{2}$ in (32) are the learning coefficients.

$$
w_{i}=w_{\max }-1 / l_{\max }\left(w_{\max }-w_{\min }\right)
$$

Where, 'Imax', ' 1 ' , 'wmin' and 'wmax' are maximum iterations, the current iteration, and the minimum and maximum weights respectively.

\section{IV.II.II Optimization using GWO}

The Grey Wolf optimization (GWO) algorithm is a swarm based intelligent technique derived from praying and hunting 
habits of grey wolves. The grey wolves follow the strict hierarchy of relationship which is categorized in four different levels. Depending upon their fitness the number of wolves is categorized as alpha wolves, beta wolves, delta wolves and omega wolves. As per the social levels of all four categories of wolves, the first level in the hierarchy is the alpha wolves which are responsible for the decision making of preying and hunting. The level two are the beta wolves which are next to the alpha wolves and considered as the advisor of the alpha one. The third level in the category is the delta wolves which are considered as the subordinates to the above level. They dominate the omega wolves which are the weakest among all the groups of the grey wolves.

The hunting behavior of the grey wolves can be explained in three different stages named searching the prey, encircling it and then attacking the prey. The first two can be considered under the exploring part and the later under the exploiting part of the hunting process. In exploration part the grey wolves explore the boundaries for the prey, and when they find some prey they encircle it from all the boundaries. Once the prey is unable to move, they attack on it.

In the searching process of the optimization algorithm similar procedure is followed as the grey wolves are performing for searching the prey. The procedure can be explained as follows. We will do some kind of searching activity, we will encircle the position by the search agents, and then we will keep updating the position of these search agents, so that the position of omega can be updated.

\section{b) GWO algorithm implementation}

As discussed in the previous section the hunting process is divided into three steps of exploration and exploitation. In the exploration process, vector $\vec{P}$ is generated, which is a random value that a wolf generates every time in the searching process and calculated as in (35), where $\vec{p}$ is a linear variable whose value is decreased from 2 to 0 as the search proceed for next iteration and $b_{1}$ is a random number in the range of [0 1$]$.

$$
\vec{P}=2 \cdot \vec{p} \cdot b_{1}-\vec{p}
$$

In the process of searching for prey, the wolves diverge from each other for finding the prey and when they find the prey they converge to the specific position. In the process of exploration, the divergence and convergence of the wolves depend on the value of $\vec{P}$. If the value of $|\vec{P}|>1$, that means that they should diverge from each other to find better one if $|\vec{P}|<1$, it means that it is the time to attack on the prey.

The encirclement is an important part in terms of attacking and hunting the goal so that the goal is surrounded by the search agent and there would be better chance of hunting the prey. The encirclement is realized by the following equations (36). In (36) $\vec{C}$ is the coefficient whose value is generated as shown in (37). Where, $b_{2}$ is another random number. $\overrightarrow{f_{p}}(t)$ is the position of the prey. $\vec{f}(t)$ is the position of search agent. The $\vec{f}(t+1)$ is the fitness value of any specific agent that how closer it is from the goal. It is used to further generate the next iteration search positions. According to the fitness value of the search agents it is decided that who will become alpha, beta, delta and omega agents. With the use of these equations the search agents update their position adjusting the position of vectors $\vec{P}$ and $\vec{C}$.

$$
\begin{aligned}
& \vec{z}=\left|\vec{C} \cdot \overrightarrow{f_{p}}(t)-\vec{f}(t)\right| \\
& \vec{C}=2 \cdot b_{2} \\
& \vec{f}(t+1)=\overrightarrow{f_{p}}(t)-\vec{P} \cdot \vec{z}
\end{aligned}
$$

For mathematical model of hunting behavior of the wolves, it is assumed that the alpha, beta and delta agents have best knowledge of the potential location of prey. That means, according to fitness value best three solutions are assigned to alpha, beta and delta search agents. According to their information the other search agents like omega improve their position so that they get the chance to become alpha agent. The concept is realized by following (39). Where, $\vec{f}_{\alpha}, \vec{f}_{\beta}$ and $\vec{f}_{\delta}$ are the specific position of particular prey like alpha, beta and delta respectively. Using the eq. (40), the fitness value is calculated for all the search agents starting from $\vec{f}_{1}$ to $\vec{f}_{n}$ and among those best three positions become alpha, beta and delta. With these three best values the next position of prey is calculated as (41) which the centroid (arithmetic mean) value of three positions. The iterations will get continue until the proper position of prey is reached. At the end of all the iteration $\vec{f}_{\alpha}$ is the best position required.

$$
\begin{aligned}
& \left.\begin{array}{rl}
\vec{z}_{\alpha}= & \left|\vec{C}_{1} \cdot \vec{f}_{\alpha}(t)-\vec{f}(t)\right|, \vec{z}_{\beta}=\left|\vec{C}_{2} \cdot \vec{f}_{\beta}(t)-\vec{f}(t)\right|, \vec{z}_{\delta} \\
= & \left|\vec{C}_{3} \cdot \vec{f}_{\delta}(t)-\vec{f}(t)\right|
\end{array}\right\} \\
& \left.\begin{array}{rl}
\vec{f}_{1}(t) & =\vec{f}_{\alpha}(t)-\vec{P}_{1} \cdot \vec{z}_{\alpha}, \vec{f}_{2}(t)=\vec{f}_{\beta}(t)-\vec{P}_{2} \cdot \vec{z}_{\beta}, \vec{f}_{3}(t) \\
& =\vec{f}_{\delta}(t)-\vec{P}_{3} \cdot \vec{z}_{\delta}
\end{array}\right\} \\
& \vec{f}(t+1)=\frac{\left[\vec{f}_{1}(t)+\vec{f}_{2}(t)+\vec{f}_{3}(t)\right]}{3}
\end{aligned}
$$




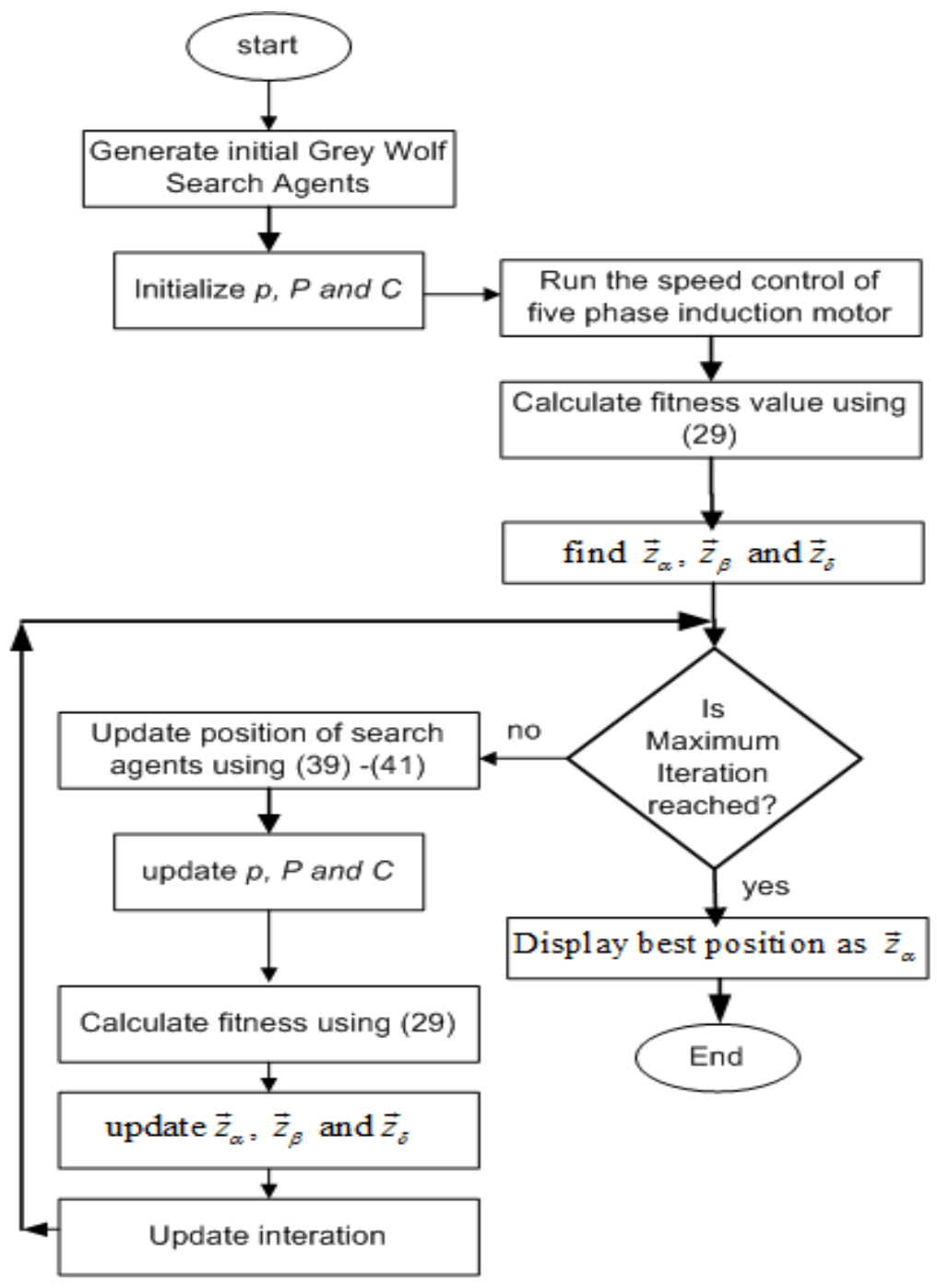

Figure 6. Frame work of GWO algorithm for speed controller optimization

\section{SIMULATION RESULTS AND DISCUSSION}

The proposed fault tolerant FPIM with optimized gains using PSO and GWO algorithm is simulated in MATLAB/ Simulink environment. The FPIM model parameters used for simulation study are as shown in Table 1.

Table 1. FPIM Parameters

\begin{tabular}{|l|l|l|l|}
\hline$S=2 \mathrm{HP}$ & $V p h=220 \mathrm{~V}$ & $I p h=2.1 \mathrm{~A}$ & $f=50 \mathrm{~Hz}$ \\
\hline$R_{s}=10 \Omega$ & $R_{r}=6.3 \Omega$ & $L s=0.46 \mathrm{H}$ & $L_{r}=0.46 \mathrm{H}$ \\
\hline$L_{m}=0.42 \mathrm{H}$ & $B=0.008$ & $J=0.03$ & $P=2$ \\
\hline
\end{tabular}

For the optimal estimation of the PI speed controller parameters PSO and GWO optimization algorithms are applied. The parameters used for the algorithm implementation are listed in Table 2. For fair comparison between two algorithms the number of search agents and maximum iterations are kept same for both the algorithms.
Table 2. Parameters of the Algorithms

\begin{tabular}{|l|l|l|}
\hline Algorithm & Parameters & Value \\
\hline \multirow{4}{*}{ GWO } & Number of Search Agents & 20 \\
\cline { 2 - 3 } & Maximum Iteration & 10 \\
\hline \multirow{4}{*}{ PSO } & Number of Search Agents & 20 \\
\cline { 2 - 3 } & Maximum Iteration & 10 \\
\cline { 2 - 3 } & Learning Coefficient b1 & 2 \\
\cline { 2 - 3 } & Learning Coefficient b2 & 2 \\
\cline { 2 - 3 } & Minimum Inertial weight $w_{\min }$ & 0.1 \\
\cline { 2 - 3 } & Maximum Inertial weight $w_{\max }$ & 0.9 \\
\hline
\end{tabular}


The variation of cost function is shown in Fig 7 and the zoomed view of the convergence curve is shown in Fig 8. It can be seen from the fig. 8 that the GWO algorithm converges faster as compared to PSO. The detailed comparison of both the algorithms is shown in Table 3.

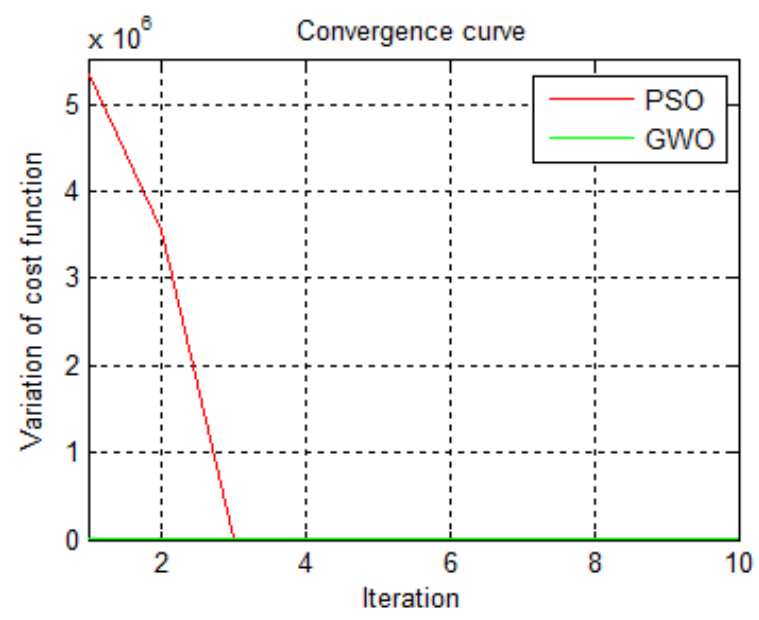

Figure 7. Variation of convergence curves

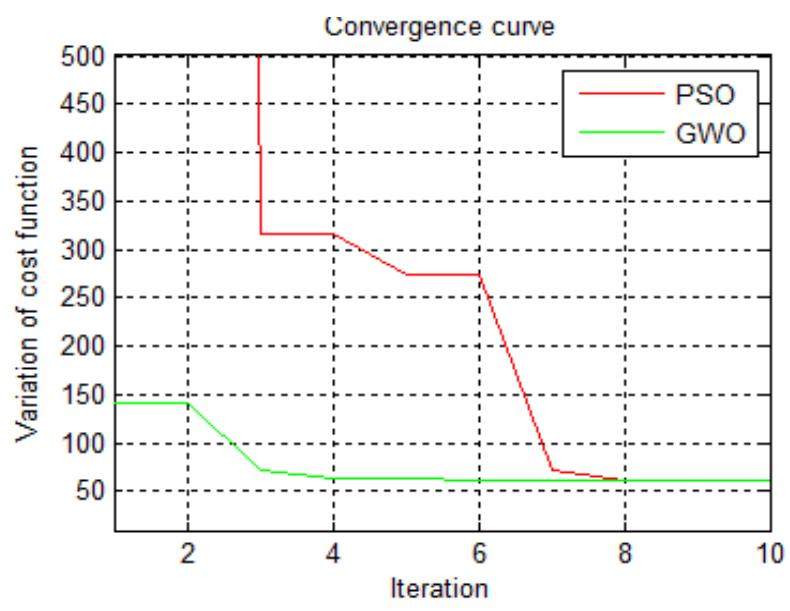

Figure 8. Zoomed view of variation of cost function

Table 3. Comparison of various parameters for algorithms

\begin{tabular}{|c|c|c|c|c|}
\hline $\begin{array}{c}\text { Optimization } \\
\text { algorithm }\end{array}$ & $\begin{array}{c}\text { Cost } \\
\text { function } \\
\text { value }\end{array}$ & $\begin{array}{c}\text { Number of } \\
\text { iterations } \\
\text { required to } \\
\text { settle cost } \\
\text { function }\end{array}$ & $K_{p}$ & $K_{i}$ \\
\hline PSO & 63.5735 & 8 & 0.4327 & 10 \\
\hline GWO & $\mathbf{6 1 . 2 9 5 3}$ & $\mathbf{4}$ & 0.38079 & 9.5419 \\
\hline
\end{tabular}

The PI speed controller performance is tested under healthy and fault tolerant mode of operation with optimal gains obtained using both the algorithms. For the underdamped system the response time is calculated at $100 \%$ of the final value approached for the first time, and settling time is calculated at $2 \%$ of the commanded value. From the results obtained with both the optimization algorithm following comparisons can be made:

\section{V.I Controller performance under prefault healthy mode of operation}

The motor performance is observed for three different test groups: First is an acceleration performance or free characteristics. Next performance is disturbance rejection behavior tested under step load condition. The third test conditions are trapezoidal speed with step change in load torque.

1) Motor starting performance at rated speed under noload torque condition

Initially the FPIM is accelerated up to the rated speed with noload applied to it. The dynamic performance is observed with the optimally tuned gains obtained using both the algorithms. The speed response dynamics of FPIM is plotted in fig 9. The fig 9a shows the time response of motor at reference speed of $157 \mathrm{r} / \mathrm{s}$ at noload applied.

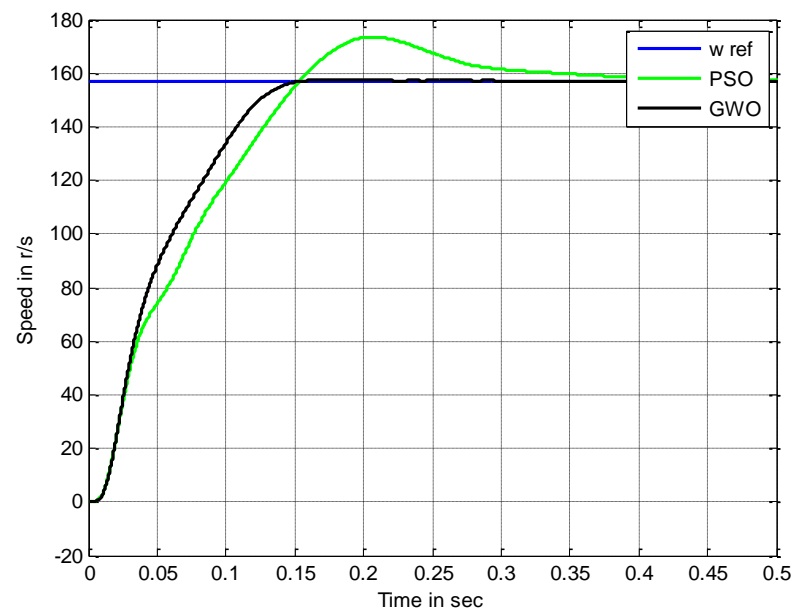

Figure 9a. Acceleration performance at reference speed of $157 \mathrm{r} / \mathrm{s}$

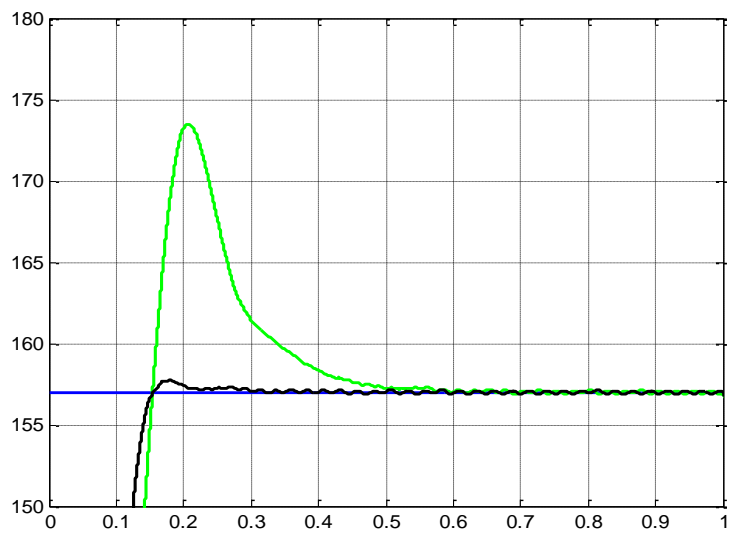

Figure 9b. Zoomed view of the acceleration performance at $157 \mathrm{r} / \mathrm{s}$ 
The zoomed view of the response is shown in fig $9 \mathrm{~b}$. The comparative details of time response parameters for the test condition are tabulated in Table 4 . The various performance indices like IAE, ISE, ITAE and ITSE are tabulated in Table 5 for different starting torque condition at reference speed of $157 \mathrm{r} / \mathrm{s}$. It is clear from the obtained results that the PI controller with gains optimized using GWO algorithm provides better results as compared to that with PSO.

Table 4. Comparison of optimization algorithms for PI tuning

\begin{tabular}{|l|c|c|}
\hline Optimization Technique & PSO & GWO \\
\hline$K_{p}$ & 0.4327 & 0.38079 \\
\hline$K_{i}$ & 10 & 9.5419 \\
\hline Settling Time $\left(t_{s}\right)$ & $0.45 \mathrm{sec}$ & $0.3 \mathrm{sec}$ \\
\hline Peak Overshoot $(\% M p)$ & $10 \%$ & $0.63 \%$ \\
\hline Response Time $\left(t_{r}\right)$ & $0.25 \mathrm{Sec}$ & $0.2 \mathrm{sec}$ \\
\hline
\end{tabular}

\section{2) The disturbance rejection behavior at rated speed of $157 \mathrm{r} / \mathrm{s}$}

The disturbance rejection behavior under healthy mode of operation is test by applying load torque at steady state speed of $157 \mathrm{r} / \mathrm{s}$. The dynamic behavior of the FPIM under the application of $8 \mathrm{Nm}$ of load torque is plotted in fig. 10. The fig. 10 shows performance of the controller on mechanical speed, electromagnetic torque and stator current variation for both the algorithm under application of $8 \mathrm{Nm}$ of load torque. The load is applied at $1.3 \mathrm{~s}$ and removed at $2.5 \mathrm{~s}$. The detailed disturbance rejection analysis for application of various load torques in healthy condition is tabulated in Table 6 .

Table 5. Comparative analysis of performance indices for optimization algorithms under healthy mode of operation

\begin{tabular}{|c|c|c|c|c|c|c|}
\hline \multirow{2}{*}{$\begin{array}{c}\text { Starting } \\
\text { Load } \\
\text { Torque }(\mathrm{Nm})\end{array}$} & \multirow{2}{*}{ Algorithm } & \multicolumn{4}{|c|}{ Performance Indices } & \multirow{2}{*}{$\begin{array}{c}\text { Total } \\
\text { Indices }\end{array}$} \\
\hline & & IAE & ISE & ITSE & ITAE & \\
\hline \multirow{2}{*}{0} & PSO & 21.5655 & 1143 & 8.884 & 89.8244 & 1263.274 \\
\hline & GWO & 8.6356 & 858.67 & 0.3590 & 21.2731 & 888.938 \\
\hline \multirow{2}{*}{2} & PSO & 19.7212 & 1159 & 7.141 & 72.3025 & 1258.1647 \\
\hline & GWO & 9.4738 & 901.73 & 0.4853 & 24.15 & 935.8391 \\
\hline \multirow{2}{*}{4} & PSO & 18.1296 & 1192 & 5.377 & 61.195 & 1276.7016 \\
\hline & GWO & 10.6902 & 959.012 & 0.6949 & 28.7132 & 999.1101 \\
\hline \multirow{2}{*}{6} & PSO & 16.8384 & 1244 & 3.6913 & 57.3466 & 1321.8763 \\
\hline & GWO & 12.5511 & 1041 & 1.0830 & 37.5069 & 1092.141 \\
\hline \multirow{2}{*}{8} & PSO & 16.139 & 1318 & 2.1717 & 63.5735 & 1399.884 \\
\hline & GWO & 16.194 & 1188 & 2.1548 & 61.2953 & 1267.6441 \\
\hline
\end{tabular}




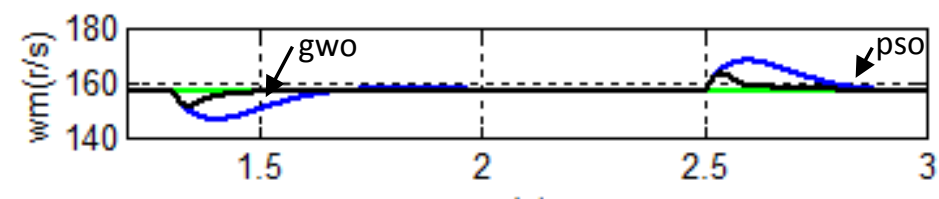

$t(s)$
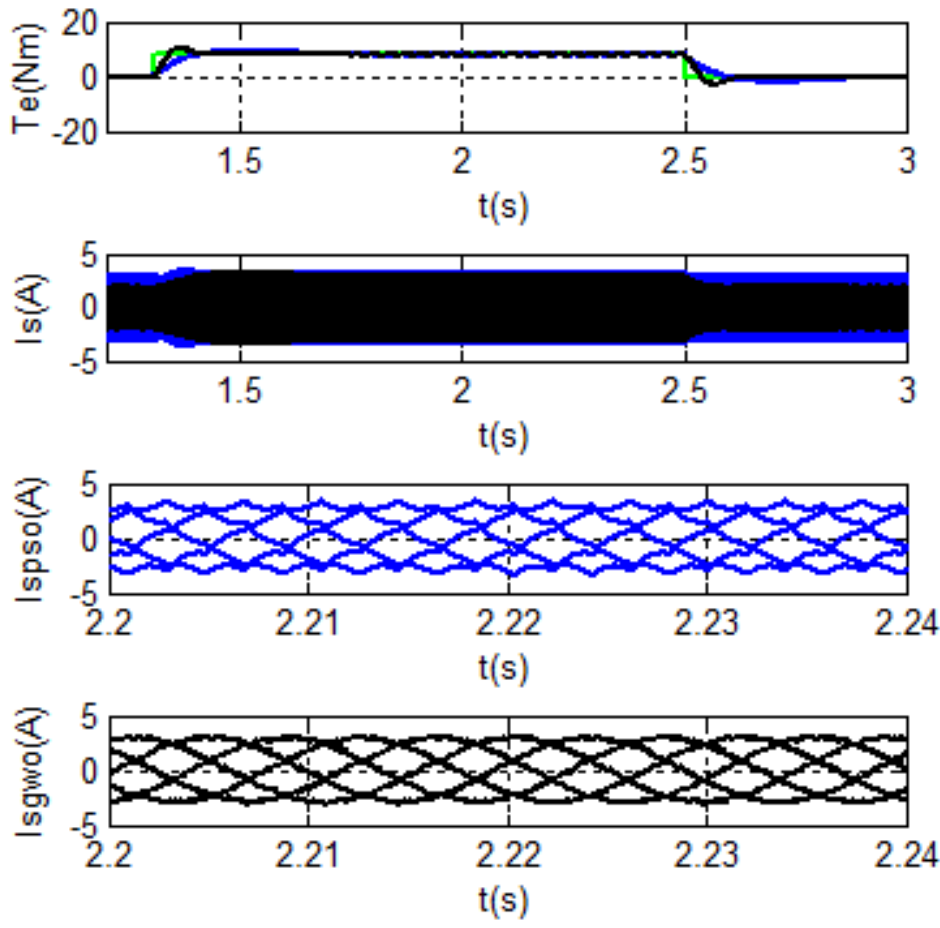

Figure 10. Disturbance rejection behaviour on application of $T_{L}=8 \mathrm{Nm}$ under healthy mode of operation

Table 6. Comparison of algorithm for disturbance rejection behavior under healthy mode of operation

\begin{tabular}{|c|c|c|c|c|c|}
\hline \multirow{3}{*}{ Load torque } & \multirow{2}{*}{ Algorithm } & \multicolumn{2}{|c|}{ Upon application of $T_{L}$} & \multicolumn{2}{c|}{ Upon removal of $T_{L}$} \\
\cline { 3 - 6 } & & $\begin{array}{c}\text { Speed undershoot } \\
(\mathrm{r} / \mathrm{s})\end{array}$ & $T_{\text {recov } \text { ery }}(\mathrm{s})$ & Speed overshoot (r/s) & $T_{\text {re cov } \text { ery }}(\mathrm{s})$ \\
\hline \multirow{3}{*}{2} & PSO & 2.6 & 0.7 & 2.6 & 0.5 \\
\cline { 2 - 6 } & GWO & 1.4 & 0.1 & 1.4 & 0.12 \\
\hline \multirow{3}{*}{4} & PSO & 6 & 0.7 & 5.3 & 0.76 \\
\cline { 2 - 6 } & GWO & 2.7 & 0.13 & 2.9 & 0.15 \\
\hline \multirow{3}{*}{6} & PSO & 7.5 & 0.7 & 8 & 0.8 \\
\cline { 2 - 6 } & GWO & 4.2 & 0.4 & 4.4 & 0.36 \\
\hline & PSO & 9.5 & 0.8 & 9.5 & 0.8 \\
\hline
\end{tabular}

\section{V.II Controller performance under Post fault operation}

The operation of motor under fault condition may be considered as a parametric disturbance in system. The controller performance is tested under the open circuit fault condition. The fault is applied at $4 \mathrm{sec}$ in ' $a$ ' phase as explained in section 2 under different load torque condition on
FPIM. The fault tolerance technique (FTT) as explained in section 3 is applied at $6 \mathrm{~s}$. In practice it is to be applied immediately as soon as the fault gets detected. In this paper it is applied after $2 \mathrm{sec}$ to differentiate the controller behavior under fault condition with fault tolerant behavior. Also this may be the case if application of FTT is delayed due to some 
reasons. The corresponding motor dynamics under faulty mode of operation is plotted in fig 11. It shows (i) mechanical speed, (ii) torque and (iii) \& (iv) current response for two different algorithms after application of fault at $4 \mathrm{sec}$. It can be seen from that the after occurrence of fault the phase ' $a$ ' current becomes zero (blue) and remaining healthy current become unbalanced with increased magnitudes and subsequently high increase in torque ripples. The fig 12 shows same set of quantities after application of FTT at 6 sec. From the current waveforms it is clear that after application of FTT the remaining healthy currents become balanced with subsequent reduction in torque ripples. The corresponding results for dynamic behavior of FPIM are tabulated in Table 7.

(i)

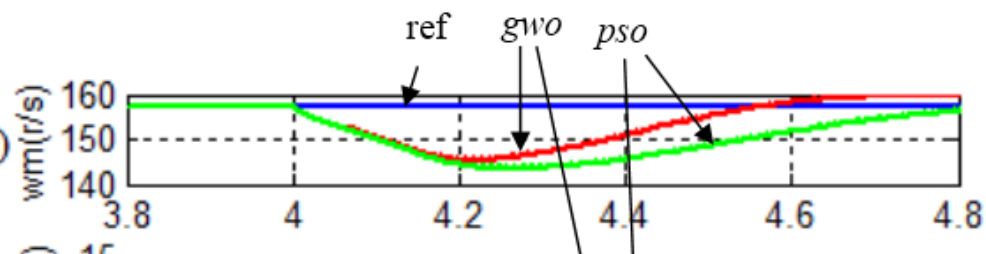

(ii)

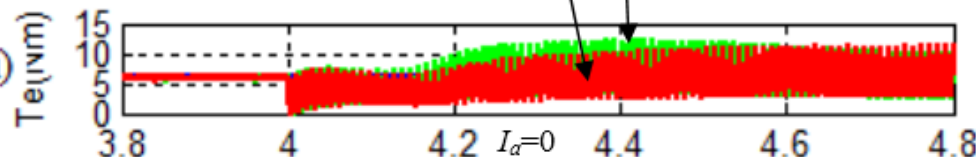

(iii)

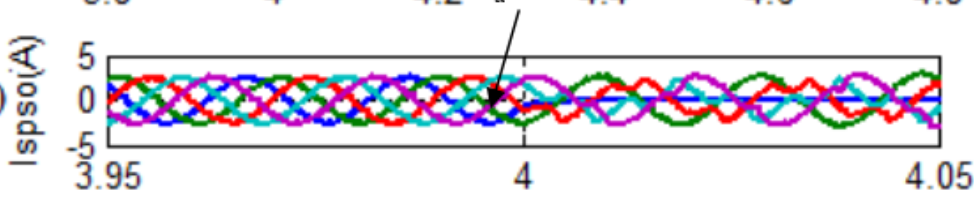

(iv)
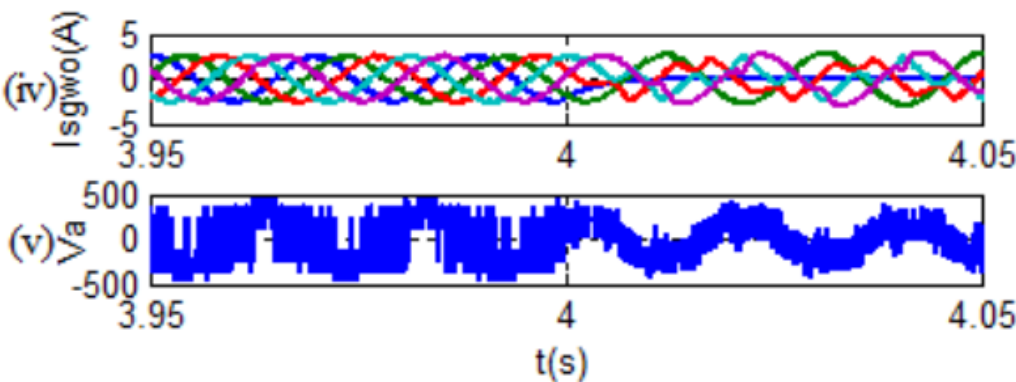

Figure 11. Motor dynamics under post fault mode of operation

(i)
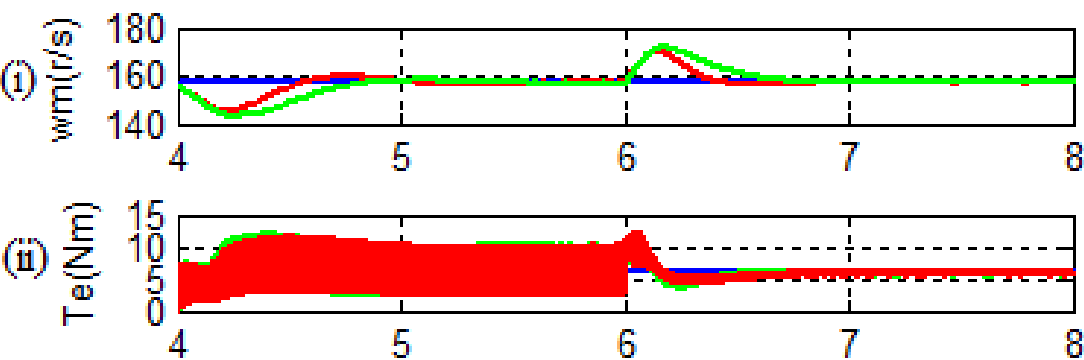

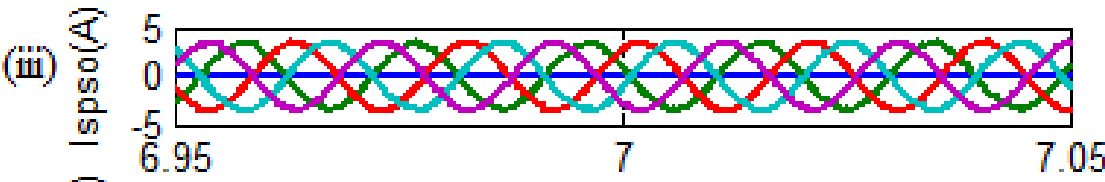

(iv)
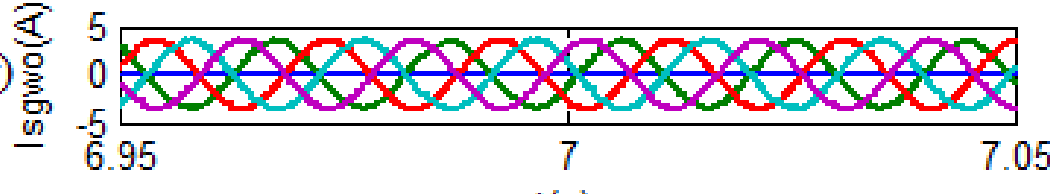

$t(s)$

Figure 12. Motor dynamics under fault tolerant operation (red-GWO, green-PSO in (i) and (ii)) 
International Journal of Engineering Research and Technology. ISSN 0974-3154, Volume 13, Number 9 (2020), pp. 2318-2331

(C) International Research Publication House. https://dx.doi.org/10.37624/IJERT/13.9.2020.2318-2331

Table 7. Comparison of algorithm for dynamic behavior under post fault mode of operation

\begin{tabular}{|c|c|c|c|c|c|}
\hline \multirow{2}{*}{$\begin{array}{c}\text { Load torque } \\
(\mathrm{Nm})\end{array}$} & \multirow{2}{*}{ Algorithm } & \multicolumn{2}{|c|}{$\begin{array}{c}\text { Upon occurrence of fault } \\
\text { Upon application of FTT }\end{array}$} \\
\cline { 3 - 6 } & $\begin{array}{c}\text { Speed } \\
\text { undershoot(r/s) }\end{array}$ & $T_{\text {recovery }}(\mathrm{s})$ & $\begin{array}{c}\text { Speed } \\
\text { overshoot (r/s) }\end{array}$ & $T_{\text {recovery } \text { (s) }}$ \\
\hline \multirow{2}{*}{2} & PSO & 3.2 & 1.5 & 4 & 1 \\
\cline { 2 - 6 } & GWO & 2.4 & 0.5 & 3.2 & 0.5 \\
\hline \multirow{3}{*}{4} & PSO & 8.2 & 1.7 & 9.8 & 1.2 \\
\cline { 2 - 6 } & GWO & 7 & 0.7 & 8.3 & 0.7 \\
\cline { 2 - 6 } & PSO & 12.5 & 1.8 & 13 & 1.3 \\
\hline \multirow{2}{*}{8} & GWO & 11 & 0.9 & 12 & 0.5 \\
\cline { 2 - 6 } & PSO & 14 & 1.9 & 14 & 0.7 \\
\hline
\end{tabular}

The tabulated results in Table 5 and Table 6 verify efficient capability of GWO algorithm as compared to PSO under healthy condition obtained in noload and load condition. The fault tolerant behavior results in Table 7 shows improved capability of controller with GWO algorithm to resume the speed quickly under fault and fault tolerant mode of operation.

\section{CONCLUSION}

The objective of this paper is to enhance the dynamic performance of FPIM under healthy, faulty and fault tolerance condition. The contribution of the work is as follows:

- In this paper rotor flux oriented speed control of five phase induction motor under healthy and open circuit fault condition is analyzed for various speed-torque profiles. The fault tolerant performance is obtained through redefinition of reference current under fault condition.

- This paper proposes GWO based optimized speed PI controller which works equally well under healthy and faulty condition.

- The optimization of Proportional -Integral controller is obtained through PSO and GWO optimization Techniques. The optimization algorithm provides the effective PI tuning with reduced efforts with significant reduction if the execution time. The GWO takes lesser iteration for the tuning process with less number of execution parameters.

- The effectiveness of controller performance for PSO and GWO optimization algorithms is compared through various time response comparisons under healthy and open circuit fault operation of the five phase induction motor.

- The application of proposed optimized controller is highly suitable for high performance and reliable electric vehicle drive where speed and load torque pattern is highly non linear and undeterministic.

\section{REFERENCES}

[1] C. Gor, P. Gupta, V. Shah and M. Lokhande, "Real time simulation of multiphase induction motor for electric vehicle using RT-Lab", IECON 2017 - 43rd Annual Conference of the IEEE Industrial Electronics Society, Beijing, 2017, pp. 6646-6651.

[2] Consoli, Alfio. "Special Section on Robust Operation of Electrical Drives." IEEE Transactions on Power Electronics 27, no. 2 (2012): 476-478.

[3] Duran, Mario J., and Federico Barrero. "Recent advances in the design, modeling, and control of multiphase machines - Part II." IEEE Transactions on Industrial Electronics 63, no. 1 (2015): 459-468.

[4] H. Xu, H. A. Toliyat, and L. J. Petersen, "Resilient current control of five-phase induction motor under asymmetrical fault conditions," in Proc. 17th Annu. IEEE Appl. Power Electron. Conf. Expo., 2002, pp. 64-71.

[5] Z. Liu, L. Peng, Y. Li, Z. Zheng, and K. Wang, "Modeling and control of 15-phase induction machine under one phase open circuit fault," in Int. Conf. Elect. Mach. Syst., 2013, pp. 2066-2071.

[6] H. S. Che, "Postfault Operation of an Asymmetrical Six-Phase Induction Machine With Single and Two Isolated Neutral Points".

[7] Guzman, H.; Duran, M.J.; Barrero, F.; Zarri, L.; Bogado, B.; Prieto, I.G.; Arahal, M.R. Comparative studyof predictive and resonant controllers in faulttolerant five-phase induction motor drives. IEEE Trans. Ind. Electron. 2016, 63, 606-617.

[8] A. S. Morsy, A. S. Abdelkhalik, A. Abbas, S. Ahmed, and A. Massoud, "Open loop V/f control of multiphase induction machine under open circuit phase faults," in Proc. 28th Annu. IEEE Appl. Power Electron.Conf. Expo., 2013., pp. 1170-1176. 
[9] Bermudez, M.; Gonzalez-Prieto, I.; Barrero, F.; Guzman, H.; Duran, M.J.; Kestelyn, X. Open-Phase Fault-Tolerant Direct Torque Control Technique for Five-Phase Induction Motor Drives. IEEE Trans. Ind. Electron. 2017, 64, 902-911.

[10] M. A. Fnaiech, F. Betin, G. Capolino and F. Fnaiech, "Fuzzy Logic and Sliding-Mode Controls Applied to Six-Phase Induction Machine With Open Phases," in IEEE Transactions on Industrial Electronics, vol. 57, no. 1, pp. 354-364, Jan. 2010.

[11] F. Betin, M. Moghadasian, V. Lanfranchi, and G. A. Capolino, "Fault tolerant control of six-phase induction machines using combined fuzzy logic and genetic algorithms," in Proc. IEEE Workshop Electr.Mach. Des.Control Diagnosis, 2013.

[12] Bousserhane IK, Hazzab A, Rahli M, Mazari B, Kamli M (2006) Position control of linear induction motor using an adaptive fuzzy integral-backstepping controller. Serbian J Electr Eng 3(1):1-17.

[13] H.Wu,W. Su, and Z. Liu, "PID controllers: Design and tuning methods," in Proc. IEEE Conf. Ind. Electron. Appl., Jun. 2014, pp. 808-813.

[14] Mirjalili, S.; Mirjalili, S.M.; Lewis, A. Grey wolf optimizer. Adv. Eng. Softw. 2014, 69, 46-61.

[15] Mahdad, B.; Srairi, K. Blackout risk prevention in a smart grid based flexible optimal strategy using grey wolf-pattern search algorithms. Energy Convers. Manag. 2015, 98, 411-429.

[16] Sulaiman, M.H.; Mustaffa, Z.; Mohamed, M.R.; Aliman, O. Using the grey wolf optimizer for solving optimal reactive power dispatch problem. Appl. Soft Comput. 2015, 32, 286-292.

[17] Yang, B.; Zhang, X.-S.; Yu, T.; Shu, H.-C.; Fang, Z.-H. Grouped grey wolf optimizer for maximum power point tracking of doubly-fed induction generator based wind turbine. Energy Convers. Manag. 2017, 133, 427443.

[18] E.Levi, "Multiphase AC machines: Chapter 3", in the Industrial electronics Handbook: Power Electronics and Motor Drives, CRC Press; London, 2011.

[19] Zaky, Mohamed S., and Mohamed K. Metwaly. "A performance investigation of a four-switch three-phase inverter-fed IM drives at low speeds using fuzzy logic and PI controllers." IEEE Transactions on Power Electronics 32, no. 5 (2016): 3741-3753. 